\title{
Use of psychotropic drugs before pregnancy and the risk for induced abortion: population-based register-data from Finland 1996-2006
}

\author{
Mika Gissler ${ }^{1,2^{*}}$, Miia Artama ${ }^{1}$, Annukka Ritvanen ${ }^{1}$, Kristian Wahlbeck ${ }^{1,3}$
}

\begin{abstract}
Background: Some, though not all studies have reported an increased risk for mental health problems after an induced abortion. Problems with design and data have compromised these studies and the generalisation of their results.

Methods: The Finnish Medication and Pregnancy database ( $N=622671$ births and 114518 induced abortions for other than fetal reasons) in 1996-2006 was utilised to study the use of psychotropic drugs in the three months before a pregnancy ending in a birth or an induced abortion.

Results: In total $2.1 \%$ of women with a birth and $5.1 \%$ of women with an induced abortion had used a psychotropic medicine 0-3 months before pregnancy. Psychotropic drug users terminated their pregnancies (30.9\%) more often than other pregnant women (15.5\%). Adjustment for background characteristics explained one third of this elevated risk, but the risk remained significantly increased among users of psychotropic medicine (OR 1.94, 95\% confidence intervals 1.87-2.02). A similar risk was found for first pregnancies (30.1\% vs. 18.9\%; adjusted OR $1.53,95 \%$ confidence intervals 1.42-1.65). The rate for terminating pregnancy was the highest for women using hypnotics and sedatives (35.6\% for all pregnancies and $29.1 \%$ for first pregnancies), followed by antipsychotics (33.9\% and 36.0\%) and antidepressants (32.0\% and 32.1\%).

Conclusions: The observed increased risk for induced abortion among women with psychotropic medication highlighs the importance to acknowledge the mental health needs of women seeking an induced abortion. Further studies are needed to establish the impact of pre-existing differences in mental health on mental health outcomes of induced abortions compared to outcomes of pregnancies ending in a birth.
\end{abstract}

\section{Background}

The connection of induced abortion and subsequent mental health problems is controversial. Studies from countries with free or relatively liberal abortion legislation have suggested that women experiencing an induced abortion have a higher risk for depression [1-5], anxiety [2,5-10], suicide [11,12], suicidal behaviour [2], substance use disorders [2], and any mental health problem requiring outpatient treatment [13] after the procedure. In most of these studies, the available confounding factors did not explain the elevated risk for harmful outcomes.

\footnotetext{
* Correspondence: mika.gissler@thl.fi

${ }^{1}$ THL National Institute for Health and Welfare, Helsinki, Finland
}

Some other studies, however, have reported no elevated risk for any psychiatric disorder [14], anxiety $[7,15]$ or depression $[1,5,16,17]$ among women who had experienced induced abortion. In Israel, pregnancy termination has been shown to result in a significant reduction in the pre-abortion psychological distress level [18]. A Swedish study reported no suffering or any subsequent regret or negative effects one year after termination [19]. Studying welfare more broadly, a study from New Zealand reported that young women who became pregnant before age 21 and terminated their pregnancy had even better outcomes on education, income, welfare dependence and domestic violence compared to young women who did not seek an abortion [20]. A recent review [21] concluded that in 21 eligible studies on the connection of induced abortion and long-term mental 
health outcomes, 8 reported neutral, 6 negative, and 7 mixed findings.

Two reviews have concluded that studies on postabortion mental health problems often face significant problems related to their design or data $[21,22]$. Terminated pregnancies are usually compared with pregnancies ending in a birth, but it would be essential to disaggrate them by pregnancy intention and to analyse intended and unintended (i.e. unwanted and mistimed) pregnancies separately. Information on pregnancy intention prior to pregnancy is, however, seldom available. Retrospective collection of such data may be biased, and the data remains unavailable in routinely collected databases.

Another major problem is that the mental health measurement is not always based on validated diagnostic instruments [21], which can be collected either prospectively or retrospectively from medical records and by using surveys. In register studies, the mental health measurements have been based on physician's diagnosis on inpatient or outpatient care [13] or, in case of suicide, on main cause of death $[11,12]$.

The third major problem is how confounders are controlled. In several studies, the number of background variables describing common determinants of mental health has been limited, and important determinants have remained unavailable. Information on pre-existing mental health status has seldom been available, even though it has been shown to be an important explanatory factor for the increased risk for negative mental health outcomes in several $[7,14]$, though not in all studies [16]. Since induced abortion and mental health problems share same risk factors - such as young age [12], poor socioeconomic circumstances, violence [3,7], and rape history [7] - the causality between induced abortion and subsequent mental health problems cannot be straightforwardly concluded without taking into consideration their common determinants.

Our aim was to clarify the pre-existing mental health status among pregnant women by using the Medication and Pregnancy database with information on all births and induced abortions in Finland in 1996-2006. We used the purchase of psychotropic drugs in the three months before pregnancy as a proxy measure of mental health status and calculated the risk for terminated pregnancy among women purchasing such drugs compared to other women with no purchases. First pregnancies were separately analysed to avoid bias caused by previous pregnancies. Selective terminations of pregnancy due to fetal anomalies were excluded, since these are originally wanted pregnancies, unlike pregnancies ending in an induced abortion in general.

\section{Methods}

The nationwide Finnish Medication and Pregnancy database was utilised in this study. The data on births were based on the Medical Birth Register (MBR) and data on induced abortion on the Register on Induced Abortions and Sterilisations. Both of these registers are maintained by the National Institute for Health and Welfare (THL).

1) MBR. All live births and stillbirths of fetuses with a gestational age of 22 weeks or more or with a birth weight of 500 grams or more have been included in the register since 1987. The register data are collected from all delivery hospitals and sent to THL. The register includes the mother's and the child's personal identification numbers, maternal obstetrical and social background, health care and interventions during pregnancy and delivery, as well as the newborn's outcome until the age of seven days. Data quality studies have shown that the majority of the register content corresponded well or satisfactorily with hospital record data [23].

2) Register on Induced Abortions. This register collects data on all induced abortions performed in Finland since 1977 [24]. National legislation requires permission and an indication for terminating a pregnancy. An induced abortion can be perfomed for social reasons (age less than 17 years or 40 years or more at conception, delivered four children or more, or social circumstances), medical reasons (health of the pregnant woman, suspected or confirmed congenital anomaly or birth defect, or mother's and/or father's incapability to take care of the child) or ethical reasons (rape or incest). The legislation on induced abortions is interpreted liberally, and $97 \%$ of the pregnancy terminations during the study period were performed on social reasons. If the permission for an induced abortion is not granted, a national board will assess the case and grant the permission unless the gestational age limit of 20 weeks (24 weeks in case of confirmed congenital anomaly or birth defect) has not been passed.

Once the pregnancy has been terminated, a notification is sent to THL within one month of the procedure. The register includes women's personal identification number, information on women's background, the procedure, and complications occurring at the hospital. According to a 1993 data quality study, more than $99 \%$ of induced abortions mentioned in hospital records were reported to the register, and for most variables, agreement between the register data and the hospital record was good [24].

By using woman's personal identification number, pregnancy data was linked to information on all reimbursed psychotropic drugs, defined as Anatomic Therapeutic Classification (ATC) categories N05 and N06 
purchased in the three months prior to estimated start of pregnancy.

3) The information on drugs was retrieved from the Register on Reimbursement Drugs, established in 1994 by the Social Insurance Institution. It includes information on the purchases of drugs that have been reimbursed under the health insurance scheme, which covers virtually all drug prescriptions for all residents of Finland. The register does not include information on OTC medicines, nor medicines used in hospitals and a few non-reimbursable drugs. The information is collected from all pharmacies, and the register includes information on purchaser, drug, dispensing and prescribing physician. Information on the purchased drug includes the Nordic Commodity Number (trade name, pharmaceutical form, strength, pack size, number of DDDs per package, marketing authorisation holder, and ATC code), number of packs received, price, reimbursement, and date of prescribing [25].

The Finnish Medication and Pregnancy database for 1996-2006 included information on 622671 pregnancies ending in a birth and 117229 induced abortions. We separately analysed 243788 first pregnancies (197 120 births and 46668 induced abortions) to avoid any bias caused by previous pregnancies and their end-point (birth, induced abortion or spontaneous abortion). Induced abortions due to fetal reasons were excluded $(\mathrm{N}=2711$ and 704, respectively).

We calculated the number of terminated pregnancies per one hundred ended pregnancies (ending in a birth or an induced abortion) for total pregnancies and by the following maternal characteristics:

- year of birth or induced abortion (from 1996 to 2006)

- age at birth or induced abortion (less than 20, 20-24, 25-29, 30-34, 35-39, 40 years or more)

- region (21 central hospital districts)

- marital status (married, cohabiting, single, unknown)

- previous pregnancies $(0,1,2,3$ or more, unknown)

- previous births $(0,1,2,3$ or more, unknown)

- previous induced abortions (0, 1 or more, unknown) and

- socioeconomic position based on woman's occupation (upper-white collar worker, lower-white collar worker, blue-collar worker, student, unknown).

The following ATC categories were analysed:

- N05 or N06: any tranquilising, antidepressant or psychostimulant drug

- N05A: antipsychotics

- N05B: anxiolytics
- N05C: hypnotics and sedatives

- N06A: antidepressants

- N06B: psychostimulants and nootropics and

- N06C: psycholeptics and psychoanaleptics in combination.

Results for the ATC group N06B are not shown in the Tables due to the low rate of prescription and the small number of pregnancies $(\mathrm{N}=28)$. The odds ratios (OR) for a pregnancy ending in an induced abortion were calculated with $95 \%$ confidence intervals (CI). The ORs were futher adjusted using logistic regressions by the following background variables: year, age, region, marital status and socioeconomic position.

Ethical approval: the National Institute for Health and Welfare (THL), and the Social Insurance Institution (KELA) have given their permission to use their health data for the Pregnancy and Medicine -project. The board of the Pregnancy and Medicine project approved this study. Since the final database is anonymous, no informed consent of the registered person or a statement from the research ethical board was required.

\section{Results}

In total, 15.5 out of 100 pregnancies were terminated (Table 1). More than half of women aged less than 20 years and a quarter of women aged 40 years or more terminated their pregnancies. Single women terminated their pregnancies more than seven times more often than those who were married and more than four times more often than cohabiting, unmarried women. The connection between previous obstetrical history and termination was U-shaped, and the risk for termination was the lowest for second pregnancies and births. If the women had at least one previous induced abortion, the risk for termination more than doubled (31\% vs. $13 \%)$. Students terminated one out of three pregnancies (34\%), while the risk was significantly lower for blue-collar workers (14\%), lower-white collar workers (9\%) and upper-white collar workers (5\%).

The likelihood to terminate a first pregnancy was higher, 18.9 per 100 first pregnancies (Table 1). The maternal background risk factors were similar for all pregnancies. Compared with their subsequent pregnancies, young women aged less than 20 years (the relative risk being $25 \%$ higher), single women $(+15 \%)$ and students $(+54 \%)$ had a higher risk to terminate their first pregnancies. Similarly, the risk to terminate their first pregnancy was significantly decreased for women aged 30 years or more (the relative risk was $11 \%$ lower), for married or cohabiting women $(-15 \%)$ and for upper and lower white-collar workers $(-9 \%)$ compared to their subsequent pregnancies. 
Table 1 Background characteristics of pregnancies ending in births and induced abortions in Finland 1996-2006

\begin{tabular}{|c|c|c|c|c|c|c|}
\hline & \multicolumn{3}{|c|}{ All pregnancies } & \multicolumn{3}{|c|}{ First pregnancies } \\
\hline & Births & Induced abortions & Induced abortions, \% & Births & Induced abortions & Induced abortions, \% \\
\hline $\mathrm{N}$ & 622671 & 114518 & 15.5 & 197120 & 45964 & 18.9 \\
\hline \multicolumn{7}{|l|}{ Age } \\
\hline Less than 20 & 17517 & 24798 & 58.5 & 13202 & 21016 & 61.3 \\
\hline $20-24$ & 103343 & 27997 & 21.3 & 51647 & 14801 & 22.2 \\
\hline $25-29$ & 199249 & 21532 & 9.7 & 73937 & 6073 & 7.6 \\
\hline $30-34$ & 188793 & 18989 & 9.1 & 42969 & 2574 & 5.6 \\
\hline $35-39$ & 92810 & 14646 & 13.5 & 13235 & 1120 & 7.7 \\
\hline 40 or more & 20959 & 6556 & 23.5 & 2130 & 380 & 14.8 \\
\hline \multicolumn{7}{|l|}{ Marital status } \\
\hline Married & 376705 & 23931 & 5.9 & 95184 & 1373 & 1.4 \\
\hline Cohabiting & 150070 & 18779 & 11.1 & 62148 & 5530 & 8.1 \\
\hline Single & 85033 & 71805 & 45.7 & 35675 & 39061 & 52.2 \\
\hline \multicolumn{7}{|l|}{ Previous births } \\
\hline 0 & 257119 & 58791 & 18.6 & - & - & . \\
\hline 1 & 206033 & 20385 & 9.0 & - & - & 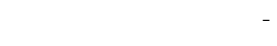 \\
\hline 2 & 97137 & 21717 & 18.2 & - & - & \\
\hline 3 or more & 61023 & 13625 & 18.2 & - & - & \\
\hline \multicolumn{7}{|c|}{ Previous induced abortions } \\
\hline 0 & 542605 & 79404 & 12.7 & - & - & \\
\hline 1 or more & 78214 & 35092 & 30.8 & - & - & \\
\hline \multicolumn{7}{|l|}{ Socioeconomic position } \\
\hline Upper-white collar w. & 108957 & 6270 & 5.4 & 37597 & 1632 & 4.1 \\
\hline Lower-white collar w. & 236149 & 23341 & 9.0 & 69481 & 5446 & 7.3 \\
\hline Blue-collar worker & 95751 & 15464 & 13.9 & 27529 & 4026 & 12.7 \\
\hline Student & 55481 & 28442 & 33.8 & 28769 & 20908 & 42.0 \\
\hline Other & 126333 & 41001 & 24.4 & 33744 & 13952 & 29.1 \\
\hline
\end{tabular}

Excluding 2711 and 704 induced abortions due to fetal reasons.

In total $2.1 \%$ of women with a birth and $5.1 \%$ of women with an induced abortion had used a psychotropic medicine 0-3 months before pregnancy. The percentages doubled in both groups, from $1.5 \%$ to $2.9 \%$ among women with a birth and from $3.9 \%$ to $7.4 \%$ among all women with induced abortion during the study period of 11 years.

By background characteristics, the use of psychotropic medicine before a pregnancy ending with a birth was increased for women aged less than 20 years and aged 35 years or more, single women, women having three or more births, women having at least one induced abortion and for blue-collar workers (Table 2). For women terminating their birth, the use of psychotropic medicine increased by age and it was also increased for single women, multiparous women, and women with repeated induced abortion. Differences by socioeconomic position were relatively small.
Among women having used psychotropic medication before pregnancy, 30.9 out of 100 pregnancies were terminated, giving a 2.5 -fold risk compared to women not using such medication (Table 3). Pregnancy termination and use of psychotropic medicine shared common risk factors, and the adjustment for background variables explained slightly more than one third of the excess risk. Even after the background standardisation, however, the risk for women having used a psychotropic medicine before pregnancy to end in a pregnancy termination was significantly increased (adjusted OR $=1.94,95 \%$ confidence interval 1.87-2.02).

By type of medication, the highest risk for terminating pregnancy was observed for women using hypnotics and sedatives $(35.6 \%$, adjusted OR $=2.25,95 \%$ CI 2.022.49), antipsychotics (33.9\%, adjusted OR $=1.85,95 \%$ CI 
Table 2 Use of psychotropic medication 0-3 months before pregnancy per 100 women

\begin{tabular}{|c|c|c|c|c|c|c|c|c|c|c|c|c|}
\hline \multirow[t]{2}{*}{ ATC code } & \multicolumn{3}{|c|}{ N05/N06 } & \multicolumn{2}{|l|}{ N05A } & \multicolumn{2}{|l|}{ N05B } & \multicolumn{2}{|l|}{ N05C } & \multicolumn{2}{|l|}{ N06A } & \multirow{2}{*}{$\begin{array}{r}\mathrm{N} 06 \mathrm{C} \\
\text { Induced } \\
\text { abortions }\end{array}$} \\
\hline & Births & $\begin{array}{r}\text { Induced } \\
\text { abortions }\end{array}$ & Births & $\begin{array}{r}\text { Induced } \\
\text { abortions }\end{array}$ & Births & $\begin{array}{r}\text { Induced } \\
\text { abortions }\end{array}$ & Births & $\begin{array}{r}\text { Induced } \\
\text { abortions }\end{array}$ & Births & $\begin{array}{r}\text { Induced } \\
\text { abortions }\end{array}$ & Births & \\
\hline Users & 13327 & 5951 & 1233 & 633 & 3381 & 1601 & 1413 & 780 & 9940 & 4667 & 379 & 110 \\
\hline $\begin{array}{l}\text { Per } 100 \\
\text { women }\end{array}$ & 2.1 & 5.1 & 0.2 & 0.5 & 0.5 & 1.4 & 0.2 & 0.7 & 1.6 & 4.0 & 0.1 & 0.1 \\
\hline \multicolumn{13}{|l|}{ Age } \\
\hline Less than 20 & 2.3 & 2.5 & 0.3 & 0.2 & 0.4 & 0.3 & 0.1 & 0.1 & 1.9 & 2.2 & 0.1 & 2.2 \\
\hline $20-24$ & 2.0 & 4.5 & 0.2 & 0.4 & 0.5 & 0.2 & 0.1 & 0.4 & 1.6 & 1.9 & 0.0 & 1.9 \\
\hline $25-29$ & 1.8 & 5.7 & 0.2 & 0.6 & 0.4 & 0.3 & 0.2 & 0.6 & 1.4 & 2.5 & 0.0 & 2.5 \\
\hline $30-34$ & 2.0 & 6.5 & 0.2 & 0.7 & 0.6 & 0.3 & 0.2 & 1.1 & 1.5 & 2.8 & 0.1 & 2.8 \\
\hline $35-39$ & 2.7 & 7.0 & 0.3 & 0.8 & 0.8 & 0.4 & 0.4 & 1.2 & 1.9 & 3.6 & 0.1 & 3.6 \\
\hline 40 or more & 3.9 & 6.4 & 0.5 & 0.6 & 1.0 & 0.9 & 0.8 & 1.4 & 2.6 & 7.8 & 0.2 & 7.8 \\
\hline \multicolumn{13}{|l|}{ Marital status } \\
\hline Married & 1.8 & 4.4 & 0.2 & 0.2 & 0.5 & 1.3 & 0.2 & 0.4 & 1.3 & 2.1 & 0.1 & 2.1 \\
\hline Cohabiting & 2.3 & 4.5 & 0.2 & 0.2 & 0.5 & 1.2 & 0.2 & 0.5 & 1.8 & 2.8 & 0.0 & 2.8 \\
\hline Single & 3.3 & 5.5 & 0.3 & 0.1 & 1.0 & 1.4 & 0.4 & 0.1 & 2.5 & 0.8 & 0.1 & 0.8 \\
\hline \multicolumn{13}{|c|}{ Previous pregnancies } \\
\hline 0 & 2.1 & 3.7 & 0.2 & 0.1 & 0.5 & 2.2 & 0.2 & 0.2 & 1.6 & 1.2 & 0.1 & 1.2 \\
\hline 1 or more & 2.2 & 6.0 & 0.2 & 0.1 & 0.6 & 1.5 & 0.2 & 0.1 & 1.6 & 0.8 & 0.1 & 0.8 \\
\hline \multicolumn{13}{|l|}{ Previous births } \\
\hline 0 & 2.2 & 4.4 & 0.2 & 0.1 & 0.5 & 1.7 & 0.2 & 0.2 & 1.7 & 0.9 & 0.1 & 0.9 \\
\hline 1 & 1.8 & 6.2 & 0.2 & 0.2 & 0.5 & 4.9 & 0.2 & 0.5 & 1.3 & 2.5 & 0.1 & 2.5 \\
\hline 2 & 2.3 & 5.7 & 0.2 & 0.2 & 0.6 & 4.7 & 0.2 & 0.4 & 1.7 & 2.5 & 0.1 & 2.5 \\
\hline 3 or more & 2.7 & 5.3 & 0.3 & 0.3 & 0.7 & 7.5 & 0.3 & 0.7 & 2.0 & 3.9 & 0.1 & 3.9 \\
\hline \multicolumn{13}{|c|}{ Previous induced abortions } \\
\hline 0 & 1.9 & 4.2 & 0.2 & 0.4 & 0.5 & 1.3 & 0.2 & 0.1 & 1.5 & 0.7 & 0.1 & 0.7 \\
\hline 1 or more & 3.5 & 7.1 & 0.4 & 1.0 & 1.1 & 2.9 & 0.5 & 0.3 & 2.6 & 1.5 & 0.1 & 1.5 \\
\hline \multicolumn{13}{|c|}{ Socioeconomic position } \\
\hline $\begin{array}{l}\text { Upper-white } \\
\text { collar w. }\end{array}$ & 1.7 & 4.8 & 0.1 & 5.1 & 0.3 & 15.5 & 0.3 & 1.5 & 1.2 & 8.1 & 0.1 & 8.1 \\
\hline $\begin{array}{l}\text { Lower-white } \\
\text { collar w. }\end{array}$ & 1.9 & 5.1 & 0.2 & 1.4 & 0.5 & 4.3 & 0.2 & 0.4 & 1.4 & 2.3 & 0.1 & 2.3 \\
\hline $\begin{array}{l}\text { Blue-collar } \\
\text { worker }\end{array}$ & 2.3 & 4.8 & 0.2 & 2.2 & 0.7 & 6.6 & 0.2 & 0.6 & 1.6 & 3.5 & 0.1 & 3.5 \\
\hline Other & 2.6 & 5.2 & 0.3 & 0.5 & 0.6 & 1.5 & 0.2 & 0.1 & 2.0 & 0.8 & 0.1 & 0.8 \\
\hline
\end{tabular}

Excluding 2711 induced abortions due to fetal reasons.

N05/N06 Any in ATC categories N05 and N06

N05A Antipsychotics

N05B Anxiolytics

N05C Hypnotics and sedatives

N06A Antidepressants

N06B Psychostimulants and nootropics

N06C Psycholeptics and psychoanaleptics in combination 
Table 3 The proportion of terminated pregnancies among women using psychotropic medicine 0-3 months before pregnancy, Finland 1996-2006

\begin{tabular}{|c|c|c|c|c|c|c|}
\hline ATC code & N05/N06 & N05A & N05B & N05C & N06A & N06C \\
\hline Terminated pregnancies per 100 & 30.9 & 33.9 & 32.1 & 35.6 & 32.0 & 22.5 \\
\hline \multicolumn{7}{|l|}{ Age } \\
\hline Less than 20 & 60.3 & 53.6 & 47.0 & 64.2 & 62.0 & 35.3 \\
\hline $20-24$ & 37.6 & 41.7 & 11.8 & 46.0 & 24.2 & 19.6 \\
\hline $25-29$ & 26.0 & 31.8 & 6.8 & 29.8 & 16.2 & 13.5 \\
\hline $30-34$ & 25.0 & 30.0 & 5.7 & 34.1 & 16.4 & 17.5 \\
\hline $35-39$ & 29.5 & 31.7 & 8.1 & 33.0 & 23.6 & 30.9 \\
\hline 40 or more & 35.5 & 28.9 & 22.3 & 38.0 & 50.3 & 32.1 \\
\hline \multicolumn{7}{|l|}{ Marital status } \\
\hline Married & 13.9 & 6.2 & 15.9 & 12.0 & 9.8 & 11.7 \\
\hline Cohabiting & 20.5 & 12.3 & 22.7 & 22.1 & 16.9 & 18.4 \\
\hline Single & 58.5 & 12.4 & 56.2 & 22.7 & 20.7 & 55.0 \\
\hline \multicolumn{7}{|l|}{ Previous pregnancies } \\
\hline 0 & 30.1 & 9.5 & 53.6 & 20.2 & 14.9 & 17.9 \\
\hline 1 or more & 31.2 & 4.7 & 29.6 & 8.8 & 7.4 & 24.3 \\
\hline \multicolumn{7}{|l|}{ Previous births } \\
\hline 0 & 31.4 & 6.6 & 43.2 & 13.7 & 11.1 & 0.0 \\
\hline 1 & 26.4 & 11.3 & 52.7 & 21.1 & 16.5 & 0.0 \\
\hline 2 & 36.2 & 19.7 & 62.7 & 29.8 & 25.1 & 28.7 \\
\hline 3 or more & 31.2 & 20.4 & 69.8 & 33.9 & 31.2 & 31.4 \\
\hline \multicolumn{7}{|l|}{ Previous induced abortions } \\
\hline 0 & 24.6 & 26.7 & 29.4 & 8.7 & 6.4 & 12.2 \\
\hline 1 or more & 47.7 & 55.0 & 54.6 & 20.4 & 21.3 & 0.0 \\
\hline \multicolumn{7}{|l|}{ Socioeconomic position } \\
\hline Upper-white collar worker & 15.1 & 76.1 & 74.3 & 25.3 & 29.4 & 8.4 \\
\hline Lower-white collar worker & 21.4 & 47.2 & 46.3 & 17.8 & 14.0 & 25.3 \\
\hline Blue-collar worker & 25.6 & 62.1 & 61.0 & 29.3 & 25.9 & 23.9 \\
\hline Other & 43.2 & 39.4 & 47.5 & 18.4 & 12.7 & 26.3 \\
\hline Crude OR & 2.51 & 2.80 & 2.60 & 3.02 & 2.62 & 1.58 \\
\hline $95 \% \mathrm{Cl}$ & $2.43-2.59$ & $2.55-3.08$ & $2.45-2.76$ & $2.76-3.29$ & $2.53-2.71$ & $1.28-1.96$ \\
\hline Adjusted OR1) & 1.94 & 1.85 & 2.02 & 2.25 & 2.00 & 1.69 \\
\hline $95 \% \mathrm{Cl}$ & $1.87-2.02$ & $1.65-2.08$ & $1.88-2.16$ & $2.02-2.49$ & $1.92-2.09$ & $1.32-2.17$ \\
\hline Explanation, \% & 37 & 53 & 36 & 38 & 38 & $<0$ \\
\hline
\end{tabular}

Excluding 2711 induced abortions due to fetal reasons.

1) Adjusted by year, age, region, marital status, socioeconomic position and gravidity.

$1.65-2.08)$ and antidepressants $(32.0 \%$, adjusted $\mathrm{OR}=$ 2.00, 95\% CI 1.92-2.09).

For first pregnancies, the share of terminated pregnancies (30.1 per 100) among women using psychotropics and their risk (adjusted OR 1.53, 95\% CI 1.42-1.65) were slightly smaller than for all pregnancies (Table 4). By type of medication, the highest risk for terminating pregnancy was found for women using antipsychotics (36.0\%, adjusted OR $=1.73,95 \%$ CI 1.39-2.16), antidepressants $(32.1 \%$, adjusted OR $=1.57,95 \%$ CI $1.44-1.71)$, and hypnotics and sedatives (29.1\%, adjusted OR $=1.74$, 95\% CI 1.36-2.22). 
Table 4 The proportion of terminated pregnancies among primigravidas using psychotropic medicine 0-3 months before pregnancy, Finland 1996-2006

\begin{tabular}{|c|c|c|c|c|c|c|}
\hline ATC code & N05/N06 & N05A & N05B & N05C & N06A & N06C \\
\hline Terminated pregnancies per 100 & 30.1 & 36.0 & 25.7 & 29.1 & 32.1 & 17.9 \\
\hline \multicolumn{7}{|l|}{ Age } \\
\hline Less than 20 & 62.4 & 56.0 & 47.5 & 64.9 & 64.0 & 30.0 \\
\hline $20-24$ & 36.5 & 44.8 & 32.1 & 43.5 & 38.1 & 26.9 \\
\hline $25-29$ & 20.8 & 29.5 & 22.6 & 24.6 & 21.3 & 9.3 \\
\hline $30-34$ & 15.9 & 25.9 & 15.7 & 14.5 & 16.9 & 6.3 \\
\hline $35-39$ & 19.8 & 28.6 & 22.0 & 22.1 & 20.6 & 27.8 \\
\hline 40 or more & 22.5 & 4.3 & 20.0 & 27.9 & 23.6 & 60.0 \\
\hline \multicolumn{7}{|l|}{ Marital status } \\
\hline Married & 3.6 & 6.5 & 3.9 & 4.1 & 3.6 & 0.0 \\
\hline Cohabiting & 14.8 & 21.3 & 13.6 & 14.8 & 14.8 & 11.8 \\
\hline Single & 58.0 & 59.1 & 51.4 & 55.2 & 60.4 & 52.6 \\
\hline \multicolumn{7}{|l|}{ Socioeconomic position } \\
\hline Upper-white collar worker & 9.3 & 10.8 & 5.4 & 5.6 & 10.9 & 3.1 \\
\hline Lower-white collar worker & 16.6 & 21.5 & 14.6 & 22.7 & 16.6 & 18.0 \\
\hline Blue-collar worker & 19.7 & 25.0 & 17.9 & 18.0 & 21.8 & 6.7 \\
\hline Other & 44.5 & 46.3 & 41.0 & 45.3 & 45.9 & 35.1 \\
\hline Crude OR & 1.88 & 2.42 & 1.49 & 1.76 & 2.07 & 0.94 \\
\hline $95 \% \mathrm{Cl}$ & $1.78-2.00$ & $2.05-2.86$ & $1.31-1.69$ & $1.47-2.12$ & $1.94-2.20$ & $0.60-1.46$ \\
\hline Adjusted $\mathrm{OR}^{1)}$ & 1.53 & 1.73 & 1.46 & 1.74 & 1.57 & 1.40 \\
\hline $95 \% \mathrm{Cl}$ & $1.42-1.65$ & $1.39-2.16$ & $1.25-1.75$ & $1.36-2.22$ & $1.44-1.71$ & $0.79-2.53$ \\
\hline Explanation, \% & 40 & 49 & 1 & 4 & 47 & $<0$ \\
\hline
\end{tabular}

Excluding 704 induced abortions due to fetal reasons.

1) Adjusted by year, age, region, marital status and socioeconomic position.

\section{Discussion}

Our data included information on more than 737000 pregnancies and several background variables. The data were derived from compulsory nationwide, population-based registers with high completeness and quality $[23,24]$. It did not, however, cover all pregnancies, since register information on pregnancies ending in spontaneous abortions before 22 weeks of gestation was not included in our database. In general, such data remain unavailable, if treated in primary health care in Finland.

We used information on purchases on psychotropic medication as a proxy of mental health disorders. Psychotropic medication is the dominating treatment approach in Finland. For instance $80 \%$ of those with an anxiety disorder using health care services for mental health reasons receive pharmacotherapy [26]. People with more severe mental health problems are more prone to seek health care [27] and thus receive prescriptions. Our proxy measure of mental ill health thus covers the majority of severe cases, but most likely will not identify all mild cases of mental ill health. A further step in the analysis would be to combine the information on purchases of psychotropic medication with hospital inpatient and outpatient data. Gathering this data both before and after pregnancy would allow analyses on the relationship between mental disorders and pregnancy in more detail.

The information on medication is more or less complete as psychotropics are not sold over the counter in Finland and practically all psychotropics are reimbursable, and thus included in our data. However, we lack information on the use of psychotropic medicine from previous prescriptions or other people's medication. We even lack information on medication given in hospital care, even though its share has diminished along the rapid deinstitutionalising of mental health services. Finally, because our data on medication were based on 
purchases, we do not have the exact information on whether the medication was actually ingested or not.

We were partly able to overcome the main methodological problems, which commonly complicate studies on the connection of mental health problems and induced abortion. We excluded induced abortions due to fetal reasons from our analysis. In these cases, these pregnancies are most often wanted, while most other induced abortions relate to unplanned or mistimed pregnancies. We did not have information on pregnancy intention on women whose pregnancy ended in a birth. Data from large Finnish birth cohort studies have shown that the proportion of unwanted pregnancies has decreased from $12.2 \%$ in 1966, before the current legislation on induced abortions, to $1.0 \%$ in 1985-1986 [28]. Thus, we can assume that only a small proportion of births are unwanted in contemporary Finland.

Second, we used register information on psychotropic medication prescribed by physicians. Such prescriptions are based on a medical diagnosis. We do, however, miss the women who have not seeked (mental) health care services, as well as women with mild mental disorders not requiring medication. Their proportions remain unknown in our study population, but the more severe mental disorder is, the less likely is it that the woman would have been misclassified.

Third, our register data included several important confounders, which were utilised in estimating the effect of women's age, previous pregnancy history, marital status, socio-economic status and region of residence on the risk of induced abortion. Other confounding factors can only be gathered by other means: by collecting medical records, by interviewing or by using postal questionnaires. Since this would not be feasible with such a large study material as we had, it remains unknown how much the unmeasured confounding explains our findings.

The Finnish Medication and Pregnancy database also included data on medication three months after the pregnancy. We did not use this data to evaluate mental disorders post-abortion, because of the use of tranquilising, antidepressant or psychostimulant drugs decreases significantly after birth due to labelling of these drugs as unsafe during lactation. According to the current national standards, 72 of the 180 psychotropic medicines in ATC classes N05 and N06 (40\%) are labelled as possibly harmful and $50(28 \%)$ clearly harmful during breastfeeding. Thus, all comparisons between births and induced abortions would have been biased. A longer follow-up period is needed to study the connection of preexisting psychotropic medication and the long-term effects of pregnancy and its end on mental health. Since our data showed that women with induced abortion differ substantially from women in general, the collection of even more detailed background information would be recommended. This includes for example data on preexisting confirmed diagnosis related to mental health, education, annual income, employment status, and social assistance, which are all available in the Finnish register system [29].

The use of psychotropic medication among young women has increased in Finland since the mid-1990s. In the general Finnish population, the number of people with at least one reimbursement for tranquilising drugs (N05) increased by $8 \%$ and that of antidepressant and psychostimulant drugs (N06) by $24 \%$ between 2000 and 2005 [30]. This trend - caused by the improved availability of new types of psychotropic medication with fewer side effects, increased identification of mental disorders and changes in help-seeking patterns - was confirmed by our data consisting of women in reproductive age.

Our nationwide data provide evidence that mental problems are more common among women who subsequently have an induced abortion, even before pregnancy. Thus, any finding of an increased post-abortion rate of mental disorders has to be contrasted against the pre-existing rate, if conclusions of the impact of induced abortion on womens mental health are to be made. Most previous studies have failed to acknowledge the high pre-existing rate, leading to biased conclusions about the impact of induced abortion on mental health.

Furthermore, we show that the excess use of psychotropic drugs among women who subsequently have an induced abortion cannot be explained solely by common background factors, such as marital status or socioeconomic position. Mental health problems severe enough to lead to the use of psychotropics are an indepedent risk factor for induced abortion. The aim to reduce the number of induced abortions is a generally accepted target for reproductive health in Finland [31]. Our results suggest that it would be important to identify actions how to promote the mental and reproductive health, especially among young women, single women and women with previous induced abortions.

The current Finnish clinical practice guideline for induced abortion does state that a post-abortion checkup visit is necessary a few weeks after the procedure to detect signs of depression and to identify the rare cases of psychosis after an induced abortion [31]. Our findings indicate that pre-existing mental disorders are more common among women who have induced abortion, and it adds justification to the current recommendation. Abiding by this recommendation may improve women's health and diminish negative health consequences postabortion.

Finland has a lower abortion rate (9/1000 women aged 15-49 years in 2008) than the other Nordic countries on 
average $(14 / 1000$ in 2007$)$ or United States $(16 / 1000$ in 2005) [32]. Even if the impact of induced abortion on mental health remains undetermined, the aim of decreasing the number of induced abortions remains important. The experience from Finland suggests that this can best be done by advancing knowledge of sexual and reproductive health and improving services related to them.

The Finnish action plan on sexual and reproductive health [33] states that sexual education should reach all children and adolescents from preschool to secondary education. Local, regional and national collaboration between different professional groups and areas should create common, cross-supportive aims for sexual education and sexual health services. These services have to be located near the clients, and if possible, as a separate youth service. The selection of contraceptives should cover all existing methods. The future aim should be that all medical examinations related to starting contraception and monitoring its use should be free-of-charge. Also a free-of-charge provision for contraceptives for young people aged under 20 has been suggested. Our results indicate that women with mental disorders and mental health problems should be especially targeted to further reduce the number of induced abortions.

Furthermore, our results indicate that the potential impact of induced abortion on women's mental health cannot be judged by comparing mental health of women with a birth to women with an induced abortion without taken into account the pre-existing mental health and vulnerability of women who choose to terminate their pregnancy.

\section{Conclusions}

Our data show that women who had used tranquilising, antidepressant or psychostimulant medication prior to their pregnancy terminate their pregnancies more often than women without such medication. Our observations should be utilised when improving care in general practice, gynaecology and mental health services. Similar, though slightly lower risk was observed for women with no previous pregnancies. This finding suggests that the pre-existing mental health status is an essential factor, which should be taken into account in trying to explain the excess of mental disorders after an induced abortion.

\section{Acknowledgements}

An earlier version of this paper with 1996-2001 data has been presented before in the Royal Statistical Society 2008 Conference in Nottingham, United Kingdom, 1-5.9.2008 with a title The Statistical Challenge of Legally Induced Abortion: Mental Health after Abortion'.

Source of funding: The database and its functions are funded by the National Agency for Medicine, National Institute for Health and Welfare (THL), and Social Insurance Institution (KELA).

\section{Author details}

${ }^{1}$ THL National Institute for Health and Welfare, Helsinki, Finland. ${ }^{2}$ Nordic School of Public Health, Gothenburg, Sweden. ${ }^{3}$ Vaasa Central Hospital, Department of Psychiatry, Vaasa, Finland.

\section{Authors' contributions}

All authors have participated in the preparation of this article and analysis, and they have accepted its final version. MG and MA prepared the analysis plan and performed them. Both MG and MA had full access to all of the data in the study and take responsibility for the integrity of the data and the accuracy of the data.

\section{Competing interests}

The authors declare that they have no competing interests.

Received: 30 April 2010 Accepted: 30 June 2010

Published: 30 June 2010

\section{References}

1. Pedersen W: Abortion and depression: A population-based longitudinal study of young women. Scand J Public Health 2008, 36(4):424-428.

2. Fergusson DM, Horwood L, Ridder EM: Abortion in young women and subsequent mental health. $J$ Child Psychol Psychiatry 2006, 47(1):16-24.

3. Taft AJ, Watson LF: Depression and termination of pregnancy (induced abortion) in a national cohort of young Australian women: the confounding effect of women's experience of violence. BMC Public Health 2008, 26(8):75

4. Cougle JR, Reardon DC, Coleman PK: Depression associated with abortion and childbirth: a long-term analysis of the NLSY cohort. Med Sci Monit 2003, 9(4):CR105-12.

5. Broen AN, Moum T, Bødtker AS, Ekeberg O: Predictors of anxiety and depression following pregnancy termination: a longitudinal five-year follow-up study. Acta Obstet Gynecol Scand 2006, 85(3):317-323.

6. Broen AN, Moum T, Bødtker AS, Ekeberg O: The course of mental health after miscarriage and induced abortion: a longitudinal, five-year followup study. BMC Med 2005, 12(3):18.

7. Steinberg JR, Russo NF: Abortion and anxiety: what is the relationship. Soc Sci Med 2008, 67(2):238-252.

8. Russo NF, Denious JE: Violence in the lives of women having abortions: Implications for public policy and practice. Professional Psychology: Research and Practice 2001, 32:142-150.

9. Bradshaw Z, Slade P: The effects of induced abortion on emotional experiences and relationships: a critical review of the literature. Clin Psychol Rev 2003, 23(7):929-958.

10. Cougle JR, Reardon DC, Coleman PK: Generalized anxiety following unintended pregnancies resolved through childbirth and abortion: a cohort study of the 1995 National Survey of Family Growth. J Anxiety Disord 2005, 19(1):137-142.

11. Gissler $M$, Hemminki $E$, Lönnqvist J: Suicides after pregnancy in Finland 1987-1994: register linkage study. Br Med J 1996, 313:1431-1434.

12. Gissler M, Berg C, Bouvier-Colle M-H, Buekens P: Injury deaths, suicides and homicides associated to pregnancy, Finland 1987-2000. Eur J Public Health 2005, 459-463.

13. Coleman PK, Reardon DC, Rue VM, Cougle J: State-funded abortions versus deliveries: a comparison of outpatient mental health claims over 4 years. Am J Orthopsychiatry 2002, 72(1):141-152.

14. Gilchrist AC, Hannaford PC, Frank P, Kay CR: Termination of pregnancy and psychiatric morbidity. Br J Psychiatry 1995, 167(2):243-248.

15. Zabin $L S$, Hirsch $M B$, Emerson MR: When urban adolescents choose abortion: effects on education, psychological status and subsequent pregnancy. Fam Plann Perspect 1989, 21(6):248-255.

16. Rees DI, Sabia JJ: The relationship between abortion and depression: new evidence from the fragile families and child wellbeing study. Med Sci Monit 2007, 13(10):CR430-6.

17. Schmiege S, Russo NF: Depression and unwanted first pregnancy: longitudinal cohort study. Br Med J 2005, 331(7528):1303.

18. Lowenstein L, Deutcsh M, Gruberg R, Solt I, Yagil Y, Nevo O, Bloch M: Psychological distress symptoms in women undergoing medical vs. surgical termination of pregnancy. Gen Hosp Psychiatry 2006, 28(1):43-7.

19. Kero A, Högberg U, Lalos A: Wellbeing and mental growth-long-term effects of legal abortion. Soc Sci Med 2004, 58(12):2559-2569. 
20. Fergusson DM, Boden JM, Horwood LJ: Abortion among young women and subsequent life outcomes. Perspect Sex Reprod Health 2007, 39(1):6-12.

21. Charles VE, Polis CB, Sridhara SK, Blum RW: Abortion and long-term mental health outcomes: a systematic review of the evidence. Contraception 2008, 78:436-450.

22. Thorp JM, Hartmann KE, Shadigan E: Long-term physical and psychological health consequences of induced abortion: a review of the evidence. Linacre Q 2005, 72(1):44-69.

23. Gissler M, Teperi J, Hemminki E, Meriläinen J: Data quality after restructuring a nationwide medical birth registry. Scand J Soc Med 1995, 23:75-80.

24. Gissler M, Ulander V-M, Hemminki E, Rasimus A: Declining induced abortion rate in Finland: Data-quality of the Abortion Register. Int $J$ Epidemiol 1996, 25:376-380.

25. Malm H, Martikainen J, Klaukka T, Neuvonen PJ: Prescription of hazardous drugs during pregnancy. Drug Saf 2004, 27(12):899-908.

26. Sihvo S, Hämäläinen J, Kiviruusu O, Pirkola S, Isometsä E: Treatment of anxiety disorders in the Finnish general population. J Affect Disorders 2006, 96:31-38.

27. Hämäläinen J, Isometsä E, Laukkala T, Kaprio J, Poikolainen K, Heikkinen M, Lindeman S, Aro $\mathrm{H}$ : Use of health services for major depressive episode in Finland. J Affect Disorders 2004, 79:105-112.

28. Rantakallio P, Myhrman A: Changes in fertility and the acceptability of pregnancies in northern Finland during the last 20 years. Int J Epidemiol 1990, 19(1):109-114.

29. Gissler M, Haukka J: Finnish health and social welfare registers in epidemiological research. Norsk Epidemiologi 2004, 14:113-120.

30. Tuori T, Gissler M, Wahlbeck K, the Nordic reference group: Mental health in the Nordic countries. Health Statistics in the Nordic Countries 2005, 149-211, NOMESCO (Nordic Medicostatistical Committee) 80. Copenhagen 2007

31. Duodecim: Clinical Practice Guideline for abortions (update 2007). [http:// www.kaypahoito.fi/kh/kaypahoito?suositus=ccs00034], As accessed 23 June 2010.

32. Jones RK, Zolna MR, Henshaw SK, Finer LB: Abortion in the United States: incidence and access to services, 2005. Perspect Sex Reprod Health 2008, 40(1):6-16

33. Ministry for Social Affairs and Health: Seksuaali- ja lisääntymisterveyden edistäminen. Toimintaohjelma 2007-2010. (In Finnish: Promotion of sexual and reproductive health. Action plan 2007-2010) Sosiaali- ja terveysministeriön selvityksiä 2006, 83.

\section{Pre-publication history}

The pre-publication history for this paper can be accessed here: http://www.biomedcentral.com/1471-2458/10/383/prepub

doi:10.1186/1471-2458-10-383

Cite this article as: Gissler et al.: Use of psychotropic drugs before pregnancy and the risk for induced abortion: population-based registerdata from Finland 1996-2006. BMC Public Health 2010 10:383.

\section{Submit your next manuscript to BioMed Central and take full advantage of:}

- Convenient online submission

- Thorough peer review

- No space constraints or color figure charges

- Immediate publication on acceptance

- Inclusion in PubMed, CAS, Scopus and Google Scholar

- Research which is freely available for redistribution 